\title{
Author Correction: Analysis of the Human Protein Atlas Image Classification competition
}

Wei Ouyang (D), Casper F. Winsnes (D), Martin Hjelmare ®D, Anthony J. Cesnik, Lovisa Åkesson, Hao Xu, Devin P. Sullivan, Shubin Dai, Jun Lan, Park Jinmo, Shaikat M. Galib, Christof Henkel, Kevin Hwang, Dmytro Poplavskiy, Bojan Tunguz, Russel D. Wolfinger, Yinzheng Gu, Chuanpeng Li, Jinbin Xie, Dmitry Buslov, Sergei Fironov, Alexander Kiselev, Dmytro Panchenko, Xuan Cao, Runmin Wei, Yuanhao Wu, Xun Zhu, Kuan-Lun Tseng, Zhifeng Gao, Cheng Ju, Xiaohan Yi, Hongdong Zheng, Constantin Kappel and Emma Lundberg (1)

Correction to: Nature Methods https://doi.org/10.1038/s41592-019-0658-6, published online 28 November 2019.

In the version of this article initially published, the institution name was missing from author Dmytro Panchenko's affiliation. The full affiliation is Kharkiv National University of Radioelectronics, Kharkiv, Ukraine. The error has been corrected in the PDF and HTML versions of the article.

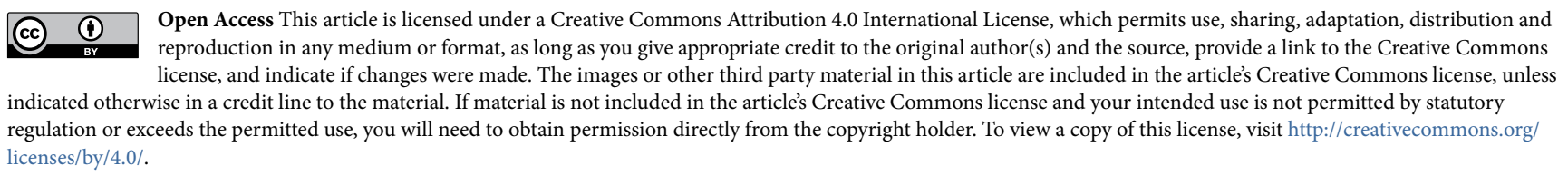

licenses/by/4.0/.

Published online: 5 August 2020

https://doi.org/10.1038/s41592-020-0937-2

() The Author(s) 2020

\section{Publisher Correction: Change-makers bring on recombinant antibodies}

Vivien Marx

Correction to: Nature Methods https://doi.org/10.1038/s41592-020-0915-8, published online 22 July 2020.

In the version of this article initially published, the text gave the impression the Institute for Protein Innovation (IPI) is affiliated with Harvard Institutes of Medicine (HIM). IPI is not an HIM institute; it is an independent organization in the HIM building. The error has been corrected in the PDF and HTML versions of the article.

Published online: 14 August 2020

https://doi.org/10.1038/s41592-020-0944-3

(C) Springer Nature America, Inc. 2020 